\title{
Stereotactic Radiosurgery Versus Active Surveillance for Asymptomatic, Skull-Based Meningiomas: An International, Multicenter Matched Cohort Study
}

Georgios Mantziaris ( $\square$ mantziaris-g@hotmail.com )

University of Virginia Health System: UVA Health https://orcid.org/0000-0002-3389-8836

Stylianos Pikis

University of Virginia Health System: UVA Health

Yavuz Samanci

Koc University: Koc Universitesi

Selcuk Peker

Koc University: Koc Universitesi

Ahmed M. Nabeel

Nasser Institute Hospital

Wael A. Reda

Nasser Institute Hospital

Sameh R. Tawadros

Nasser Institute Hospital

Amr M.N. El-Shehaby

Nasser Institute Hospital

Khaled Abdelkarim

Nasser Institute Hospital

Reem M. Emad

Nasser Institute Hospital

Violaine Delabar

University of Sherbrooke: Universite de Sherbrooke

David Mathieu

University of Sherbrooke: Universite de Sherbrooke

Cheng-chia Lee

Taipei Veterans General Hospital

Huai-che Yang

Taipei Veterans General Hospital

Roman Liscak

Na Homolce Hospital: Nemocnice na Homolce 
Jaromir Hanuska

Na Homolce Hospital: Nemocnice na Homolce

Roberto Martinez Alvarez

Ruber International Hospital: Hospital Ruber Internacional

Nuria Martinez Moreno

Ruber International Hospital: Hospital Ruber Internacional

Manjul Tripathi

PGIMER: Post Graduate Institute of Medical Education and Research

\section{Herwin Speckter}

Dominican Gamma Knife Center and CEDIMAT

\section{Camilo Albert}

Dominican Gamma Knife Center and CEDIMAT

\section{Ronald J Benveniste}

University of Miami Miller School of Medicine: University of Miami School of Medicine

\section{Greg N Bowden}

University of Miami Miller School of Medicine: University of Miami School of Medicine

\section{Dev N Patel}

NYU: New York University

\section{Douglas Kondziolka}

NYU: New York University

Kenneth Bernstein

NYU: New York University

\section{Dade L. Lunsford}

University of Pittsburgh

\section{Michael D. Jenkinson}

Walton Centre For Neurology and Neurosurgery NHS Trust: Walton Centre NHS Foundation Trust

Abdurrahman I. Islim

Walton Centre For Neurology and Neurosurgery NHS Trust: Walton Centre NHS Foundation Trust Jason P Sheehan

University of Virginia Health System: UVA Health

\section{Research Article}

Keywords: Asymptomatic, Meningioma, Skull-base, Stereotactic, Radiosurgery

Posted Date: October 27th, 2021

DOl: https://doi.org/10.21203/rs.3.rs-1005034/v1 
License: (c) (i) This work is licensed under a Creative Commons Attribution 4.0 International License. Read Full License

Version of Record: A version of this preprint was published at Journal of Neuro-Oncology on January 24th, 2022. See the published version at https://doi.org/10.1007/s11060-021-03923-3. 


\section{Abstract}

Objective: The optimal management of asymptomatic, skull-based meningiomas is not well defined. The aim of this study is to compare the imaging and clinical outcomes of patients with asymptomatic, skullbased meningiomas managed either with upfront stereotactic radiosurgery (SRS) or active surveillance.

Methods: This retrospective, multicenter study involved patients with asymptomatic, skull-based meningiomas. The study end-points included local tumor control and the development of new neurological deficits attributable to the tumor. Factors associated with tumor progression and neurological morbidity were also analyzed.

Results: The combined unmatched cohort included 417 patients. Following propensity score matching for age, tumor volume, and follow-up 110 patients remained in each cohort. Tumor control was achieved in $98.2 \%$ and $61.8 \%$ of the SRS and active surveillance cohorts, respectively. SRS was associated with superior local tumor control ( $\mathrm{p}<0.001, \mathrm{HR}=0.01,95 \% \mathrm{Cl}=0.002-0.13$ ) compared to active surveillance. Three patients $(2.7 \%)$ in the SRS cohort and six (5.5\%) in the active surveillance cohort exhibited neurological deterioration. One $(0.9 \%)$ patient in the SRS-treated and $11(10 \%)$ patients in the active surveillance cohort required surgical management of their meningioma during follow-up.

Conclusions: SRS is associated with superior local control of asymptomatic, skull-based meningiomas as compared to active surveillance and does so with low morbidity rates. Active surveillance with regular neuroimaging studies does not always detect tumor growth before symptomatic progression. SRS should be considered as an alternative to active surveillance at diagnosis of an asymptomatic skull base meningioma. If active surveillance is initially chosen, SRS should be recommended when tumor growth from the original presenting volume is noted during follow-up.

\section{Introduction}

The wider availability and increased use of neuroimaging for nonspecific symptomatology has resulted in increased detection of incidental meningiomas [1, 2]. Asymptomatic, skull base meningiomas account for up to $34 \%$ of incidentally discovered meningiomas [3]. However due to the lack of high level evidence, the optimal management of asymptomatic, skull-based meningiomas remains controversial [4-6]. Initial management options include active surveillance, resection, fractionated radiotherapy, and stereotactic radiosurgery (SRS).

The natural history of incidentally imaging-defined skull base meningiomas is unpredictable, with 39.5 to $45.7 \%$ of them demonstrating radiological progression in linear diameter measurements $[7,8]$ and $39.5 \%$ to $48.1 \%$ in volumetric studies $[3,8]$. Moreover, according to natural history studies $2.6-40 \%$ of patients with untreated, asymptomatic skull-based meningiomas will eventually experience neurological deterioration requiring treatment [4]. 
SRS has been reported as a generally safe and effective treatment option for asymptomatic skull base meningiomas [4]. In addition, SRS affords superior local tumor control as compared to active surveillance, without increasing the risk of new neurologic deficits [9]. The aim of this matched cohort study is to evaluate the efficacy and safety of SRS in the treatment of patients with asymptomatic, skullbased meningiomas.

\section{Methods}

\section{Study design and population}

This study included 307 patients managed for an incidentally diagnosed asymptomatic, skull base meningioma (SRS cohort) from 14 participating centers, as well as an observation group of 110 patients with an asymptomatic, skull-base meningioma that were initially managed with clinical and neuroimaging surveillance (observation cohort) from the Walton Centre NHS Foundation Trust, a neurosurgical center for a regional group of 18 hospitals. The participating centers obtained approval by the local institutional review boards for the study and for sharing de-identified data with the coordinating office. Prior to forwarding the data to the study coordinating investigator, a coordinator at each center verified the data for completeness.

The study included patients 16 years or older, with a single intracranial, skull-based lesion compatible on brain MRI with a meningioma, and without a history of malignancy. Study participants exhibiting neurological signs and symptoms attributable to the meningioma at the time of the diagnosis were excluded. Patients experiencing nonspecific symptoms, such as headache, nausea etc., or signs and symptoms non-localizing to the tumor site were included. All study participants underwent longitudinal clinical and neuro-imaging follow-up according to local institutional protocols.

New neurological deficits as well as adverse radiation effects (AREs) reported during the follow-up period were documented and analyzed. Additional treatments required for the management of neurological morbidity, SRS-related adverse events, or meningioma progression were recorded.

\section{Tumor and intervention definitions}

Meningiomas were defined on T1-weighted, post-contrast enhanced, brain MRI as extra-axial, dural-based, homogeneously-enhancing lesions, with or without a dural tail. Tumor progression as defined by the Response Assessment in Neuro-Oncology (RANO) criteria was noted during neuro-image follow-up [10]. In the SRS cohort, tumor volumetric assessments were done using the Gamma Knife planning at SRS and the MRI scans during follow-up.

SRS was described according to the consensus definition [11], and radiosurgery was performed using the Gamma Knife (Elekta AB, Stockholm, Sweden). SRS utilized thin-sliced $(1 \mathrm{~mm})$ axial and coronal pre- and post-contrast enhanced brain MRI and/or brain CT. A multi-isocentric approach was typically used for 
radiosurgical planning. Radiosurgical treatment parameters were selected by the local multidisciplinary treating team according to the Gamma Knife technology available at that center at the time of treatment.

\section{Outcomes}

The primary effectiveness endpoint of this study was local tumor control defined as meningioma stability or regression at last radiological follow-up according to the RANO criteria [10]. The safety endpoint of the study was defined as SRS- or tumor- attributed new neurological deficits.

\section{Statistical analysis}

All statistical analyses were performed using R programming [12] in R Studio [13]. Baseline patient and meningioma characteristics were compared between the active surveillance and SRS cohorts. Continuous variables were compared using the Student's t or Mann-Whitney $U$ tests, and categorical variables were compared using Pearson's $\chi 2$, Fischer's exact tests or Kruskal-Wallis rank sum test.

Since age at presentation, tumor volume, location of the meningioma and duration of follow-up have already been shown to affect the natural history of meningiomas $[7,8,14,15]$, in order to control for potential confounders of the treatment, the cohorts were matched. The matching process was performed using the Matchlt package for $\mathrm{R}$. The matching process was performed without replacement, in a 1:1 ratio using propensity scores derived from patient age, meningioma location, tumor volume and duration of clinical follow-up. Adequate balance was considered an absolute standardized difference of $<0.10$ between the active surveillance and SRS cohorts for the matched covariates.

Univariate and multivariate analyses of the unmatched and matched cohorts were performed for outcome measures using Cox regression analysis. Time-dependent analyses for progression-free and overall survival were performed using Kaplan-Meier curves and the differences between the function curves were analyzed using the log-rank test. Additionally, further univariate and multivariate analyses using Cox regression were performed in the unmatched SRS cohort to determine risk factors for SRSrelated adverse radiation effects and the emergence of neurological deficits.

The suggestive cutoff value for variables (tumor volume, margin dose) were determined by employing the Youden index [16]. $\mathrm{P}<0.05$ was defined as statistically significant, and all tests were two-tailed. Missing data were not imputed.

\section{Results}

\section{Unmatched cohort patient and tumor characteristics}

The unmatched cohorts included 307 SRS-treated patients and 110 patients that were managed with active surveillance for an asymptomatic, skull-based meningioma. The mean age of the SRS-treated group was 57.3 (Standard deviation (SD) \pm 13.1 ) years, and that of the active surveillance group was 63.2 $(S D \pm 11.11)$ years $(p<0.001)$. Median initial KPS was 90 [Interquartile range (IQR) 10] and 100 (IQR 10) in 
the SRS and active surveillance group respectively $(p=0.55)$. The mean meningioma volume was $4.5 \mathrm{~cm}^{3}$ $(S D \pm 4.1)$ in the SRS cohort and $3.7(S D \pm 4.8)$ in the active surveillance cohort. The median neuroimaging and clinical follow-up periods of the SRS-treated patients were 45.5 months (IQR 43.8) and 50 months (IQR 59.5) respectively, while for the conservatively managed patients both the median radiological and clinical follow-up periods was 42 months (IQR 42.3) ( $p=0.001$ and $p=0.002)$.

\section{Matched cohorts patient and tumor characteristic}

After propensity score matching for patient age, tumor location, tumor volume, and duration of radiological and clinical follow-up periods, 110 patients remained in each cohort (Table 1 ). The mean age of the SRS-treated cohort was 62.9 (SD \pm 12.3 ) years, while the mean age of the patients in the active surveillance cohort was 63.2 (SD \pm 11.1 ) years $(p=0.8)$. Median initial KPS was 100 (IQR 10) in both groups $\left(p=0.72\right.$ ). Mean meningioma volume in the SRS and active surveillance cohorts was $3.9 \mathrm{~cm}^{3}$ (SD $\pm 3.2)$ and $3.7 \mathrm{~cm}^{3}(\mathrm{SD} \pm 4.8)$, respectively $(p=0.72)$. The median neuroimaging and clinical follow-up periods of the SRS-treated patients were 46 months (IQR 36) and 50 months respectively (IQR 59.5) while for the active surveillance cohort both follow-up periods were 42 months (IQR 42.3) ( $p=0.4$ and $p=0.3$ ).

\section{Radiosurgical treatment parameters}

In the unmatched SRS cohort (Table 2), 292 (95.1\%) patients were treated with single-session SRS (sSRS). Hypofractionated SRS (hSRS) using two, three, four, and five fractions was used to treat three (1\%), four (1.3\%), two (0.7\%) and six (2\%) patients, respectively. The mean margin dose was 12.8 Gy (SD \pm 2 ), and the median number of isocenters used in treatment was 10 (IQR 8 ).

In the SRS cohort after propensity score matching (Table 2), 106 (96.4\%) patients were treated in with single-session SRS, while four (3.6\%) patients received five-fraction hSRS. The mean margin dose was 13.1 Gy (SD \pm 2.3$)$, and the median number of isocenters used was 10 (IQR 10).

\section{Radiologic and clinical outcomes in the unmatched cohorts}

In the unmatched cohorts, tumor progression was noted in two $(0.7 \%)$ patients that were treated with SRS compared to $42(38.2 \%)$ patients in the active surveillance group $(p<0.001)$. Tumor regression was achieved in 137 (44.6\%) SRS-treated patients, and it was noted in one $(0.9 \%)$ conservatively managed patient. Tumor stability was observed in $168(54.7 \%)$ of the SRS treated patients and in $67(60.9 \%)$ of patients managed with active surveillance $(p<0.001)$. None of the patients in the SRS cohort developed radiation associated malignancy during follow-up.

New neurologic deficits attributable to either tumor progression or to SRS treatment, were noted in 8 (2.6 $\%)$ patients treated with SRS as compared to $6(5.5 \%)$ patients in the active surveillance group $(p=0.2)$. In the SRS-treated cohort three ( $1 \%)$ patients exhibited trigeminal nerve neuropathies, two $(0.7 \%)$ patients presented with transitory vestibulocochlear nerve related symptoms, two patients $(0.7 \%)$ experienced seizure due to post-treatment perilesional edema that resolved after corticosteroid treatment, and one 
patient $(0.3 \%)$ facial nerve palsy. In the active surveillance cohort, three $(2.7 \%)$ presented with seizures, one $(0.9 \%)$ patient experienced motor, one $(0.9 \%)$ visual, and one $(0.9 \%)$ patient cerebellar deficits. These deficits were related to tumor progression and five of these patients were managed with resection, while one was managed conservatively.

\section{Radiologic and clinical outcomes in the matched cohorts}

In the matched cohorts (Table 1), tumor progression was noted in two (1.8\%) patients that were treated with SRS compared to $42(38.2 \%)$ patients in the active surveillance group $(p<0.001)$. Tumor regression was achieved in 39 (35.5\%) SRS-treated patients and was noted in one (0.9\%) conservatively managed patient. Tumor stability was observed in 69 (62.7\%) SRS treated patients and in 67 (60.9\%) patients that were managed with active surveillance $(p<0.001)$.

New neurologic deficits attributable to either tumor growth or SRS treatment were noted in three $(2.7 \%)$ SRS-treated patients and in six (5.5\%) patients managed with active surveillance $(p=0.89)$.

Radiological progression-free survival was in favor of the SRS group, while neurological progression-free survival was not appreciably different (Figure 1).

\section{Risk factors for tumor progression and emergence of new neurologic deficits in the combined cohorts}

Univariate and multivariate analysis for tumor progression in the unmatched, combined cohort of 417 patients revealed that upfront SRS treatment was strongly associated with local tumor control $(p<0.001$, $\mathrm{HR}=0.01,95 \% \mathrm{Cl}=0.003-0.05)$. In the matched, combined cohort of 220 patients, univariate analysis also revealed that early SRS treatment was a strong prognostic factor associated with local tumor control $(p<0.001, \mathrm{HR}=0.02,95 \% \mathrm{Cl}=0.003-0.15)$, while increasing age was a risk factor for tumor progression $(p=0.03, H R=1.03,95 \% \mathrm{Cl}=1-1.06)$. In the multivariate analysis only SRS treatment reached statistical significance $(p<0.001, \mathrm{HR}=0.01,95 \% \mathrm{Cl}=0.002-0.13)$. (Table 3)

Univariate analysis for emergence of new neurologic deficits in the unmatched, combined cohort of 417 patients revealed that increasing tumor volume was associated with a higher risk for the emergence of new neurologic deficits $(p<0.001, \mathrm{HR}=1.2,95 \% \mathrm{Cl}=1.1-1.3)$, while SRS treatment conveyed statistically significant protective effect $(\mathrm{p}<0.02, \mathrm{HR}=0.21,95 \% \mathrm{Cl}=0.06-0.79)$. Multivariate analysis revealed that the tumor volume $(p<0.001, \mathrm{HR}=1.2,95 \% \mathrm{Cl}=1.1-1.3)$ and SRS management $(\mathrm{p}<0.02, \mathrm{HR}=0.21,95 \% \mathrm{Cl}=0.06$ 0.79 ) were statistically significant risk and protective factors for new neurologic deficits, respectively. In the matched, combined cohort of 220 patients, no factors were found to be predictive of neurological morbidity. (Table 4)

\section{Risk factors associated with post-SRS adverse radiation effects and neurologic deficits}

In the unmatched cohort of patients that were treated with SRS for an asymptomatic skull-based meningioma, we sought to identify risk factors that were associated with neurological morbidity and 
asymptomatic, adverse radiation effects (AREs) at last follow-up. The suggestive cutoff value calculated using the Youden index for tumor volume and margin dose was $3.5 \mathrm{ml}$ and $13.5 \mathrm{~Gy}$, respectively.

Univariate analysis for post-SRS, asymptomatic AREs revealed that tumor volume $>3.5 \mathrm{ml}(\mathrm{p}=0.003, \mathrm{HR}=$ $4.5,95 \% \mathrm{Cl}=1.7-12)$, margin dose $>13.5 \mathrm{~Gy}(\mathrm{p}=0.02, \mathrm{HR}=2.6,95 \% \mathrm{Cl}=1.2-5.6)$, an increasing number of isocenters used $(p=0.002, \mathrm{HR}=1.1,95 \% \mathrm{Cl}=1-1.1)$ were all significant risk factors for post-treatment AREs. In multivariate analysis, tumor volume $>3.5 \mathrm{ml}(\mathrm{p}=0.02, \mathrm{HR}=3.24,95 \% \mathrm{Cl}=1.16-9.03)$ and margin dose $>13.5 \mathrm{~Gy}(\mathrm{p}=0.04, \mathrm{HR}=2.36,95 \% \mathrm{Cl}=1.02-5.5)$ were factors that were associated with the emergence of new asymptomatic AREs. (Table 5)

Univariate analysis for neurological deficits following SRS-treatment revealed that an increasing number of isocenters $(p<0.001, H R=1.1,95 \% \mathrm{Cl}=1-1.1)$ and treatment in multiple fractions $(p=0.02, H R=6.7,95 \%$ $\mathrm{Cl}=1.3-33)$ were associated with post-SRS new neurological deficits. In multivariate analysis, increasing number of isocenters reached statistical significance $(p=0.008, H R=1.05,95 \% C l=1.01-1.09)$. Tumor volume and margin dose were not associated with new neurological deficits. (Table 5)

\section{Discussion}

In our study, radiological tumor control as defined by the RANO criteria [10], was achieved in $98.2 \%$ and $61.8 \%$ of the matched SRS and active surveillance cohorts respectively, and SRS was strongly associated with asymptomatic, skull base meningioma radiological control $(\mathrm{p}<0.001, \mathrm{HR}=0.01,95 \% \mathrm{Cl}=0.002-0.13)$. In the matched SRS cohorts, five SRS patients (4.6\%) exhibited neurological deterioration compared to six patients $(5.5 \%)$ in the active surveillance cohort. No factors were found to be associated with neurological morbidity in the matched cohort analysis. In the unmatched cohorts, SRS $(p<0.02, \mathrm{HR}=0.21,95 \% \mathrm{Cl}=0.06-$ 0.79 ) was correlated with improved neurological outcome in the univariate analysis and increasing tumor volume was associated with neurological morbidity in both the univariate $(p<0.001, \mathrm{HR}=1.2,95 \% \mathrm{Cl}=1.1$ 1.3) and multivariate $(p<0.001, \mathrm{HR}=1.16,95 \% \mathrm{Cl}=1.06-1.27)$ analyses. Failure of management that necessitated further management, surgical or radiosurgical, was observed in one $(0.9 \%)$ and $13(11.8 \%)$ patients in the SRS and active surveillance cohorts, respectively. The tumor and/or neurological progression free survival of SRS treated versus active surveillance managed patients was noted to significantly separate at approximately the 3-year time point (Figure 1).

Skull base meningiomas have been described as distinct entities demonstrating a significantly different progression path compared to non-skull base meningiomas [15]. The association of skull base meningioma location and tumor growth is unclear, with studies reporting positive correlation [17], negative correlation [3] or no correlation at all [8]. Additional clinical and radiological factors that have been associated with growth potential of meningiomas, include age, peritumoral edema, hyperintense signal on T2W-MRI, and lack of calcification [18]. Even though there is limited evidence on the natural history of asymptomatic skull base meningiomas, the current proposed initial management is active surveillance with serial neuroimaging follow-up [19]. However volumetric studies of incidental, skull base meningiomas suggest that $39.5 \%$ to $48.1 \%$ will eventually demonstrate radiological progression $[3,8]$. 
While the current guidelines suggest that annual monitoring with serial neuroimaging as the preferred management option, no recommendations are provided concerning the duration of monitoring [6]. Additionally, there is no consensus about treatment indications and while clinical progression usually necessitates intervention, no recommendations are provided regarding significant radiologic progression. The concept of growth in an asymptomatic meningioma is more appropriately one of continued or further growth as the meningioma had to have grown to get to the originally identified size on MRI at the time of presentation. Contrary to active surveillance, SRS has shown favorable radiological tumor control rates with SRS for small to medium sized meningiomas being comparable to Simpson grade I resection [20]. In the current study, radiological progression rates in the matched SRS and active surveillance cohort were $1.8 \%$ and $38.2 \%$, respectively. SRS treatment conveyed significant benefit in terms of local tumor control $(p<0.001)$.

While SRS has been proven to confer excellent local tumor control, long-term active surveillance has been favored compared to SRS management of asymptomatic, skull based meningiomas due to the low but existing risk for neurological deterioration and adverse radiation effects. Overall neurological complications following radiosurgical treatment of asymptomatic meningiomas are reported at a rate of 2.6-18\%, with 3-6.8\% accounting for transient complications while $2.6-11.1 \%$ consisting of permanent, long-term deficits $[4,21,22]$. Moreover, in analyses comparing morbidity in active surveillance studies and following SRS-intervention, severity is not graded and thus complications are grouped together, preventing estimation of severe neurological complications [23]. In a meta-analysis of 675 conservatively managed meningiomas that involved 158 skull-base tumors, Sughrue et al. reported that based on their specific location, $5-61 \%$ of untreated, skull-based meningiomas demonstrated symptomatic tumor progression [7]. In a retrospective analysis of 40 conservatively managed patients with a skull base meningioma, new or worsening cranial nerve deficits developed in $11(27.5 \%)$ patients at 83 months mean clinical follow-up [24]. In this study, we report eight (2.6\%) and six (5.5\%) patients for the SRStreated and active surveillance unmatched cohorts respectively, while for the matched cohorts three (2.7 $\%)$ and six (5.5 \%) patients for the SRS-treated and active surveillance respectively. Although in the unmatched cohort patients early SRS treatment appeared to provide a statistically significant lower risk of neurological deterioration $(p=0.02)$, in the matched cohort the incidence of neurological deterioration between the two cohorts was not found to be statistically significant.

SRS appears to alter the natural history of asymptomatic, skull base meningiomas, reducing the rates of symptomatic progression, thus limiting the need for further surgical management [4]. The primary management of symptomatic meningiomas consists of resection with the aim of gross total resection (GTR) [25]. However, the close proximity of these tumors with critical neurovascular structures limits the rates of GTR as well as increases the risk for surgical morbidity [26-29]. In a recent study by Meling et al. that included 1148 surgically managed meningioma, 562 of which were skull-based, gross total resection (GTR) was achieved in $63 \%$ of the patients. Additionally, $21 \%$ of the patients experienced neurological deterioration after resection, while $3 \%$ had post-surgical complications and the 30 -day mortality rate was $2 \%$ [15]. The decreased rate of radiological and clinical progression in the SRS cohort in this study is validated by the significantly lower rate of post-SRS surgical resection (one patient or $0.9 \%$ ) compared to 
the active surveillance cohort (11 patients or 10\%), providing one additional incentive for SRS management of asymptomatic, skull base meningiomas as compared to active surveillance.

Asymptomatic, radiation-induced imaging changes, such as T2W hyper-intensity and perilesional edema, have been reported in the treatment of intracranial lesions with SRS [30, 31]. Post-treatment perilesional edema has been associated with increasing lesion volume and radiation prescription dose [32, 33]. In agreement with the current literature, in this study increasing tumor volume and margin dose appear to be correlated with the emergence of adverse radiation effects (AREs). Additionally, the risk appears to be significantly higher in tumor volumes greater than $3.5 \mathrm{~cm}^{3}(p=0.02)$ and with margin doses greater than $13.5 \mathrm{~Gy}(\mathrm{p}=0.04)$. These factors do not confer an increased risk for the emergence of new neurological benefits. (Table 5 )

\section{Limitations}

Limitations of our study include bias inherent to its retrospective design, the lack of centralized radiological review leading to inter-rater and intra-rater variability despite the use of the RANO criteria and non-standardized follow-up protocols among participating centers. Additionally, due to the requirement for exact matching in tumor location, parasellar and cavernous sinus meningiomas were not included in the matched cohort due to their absence in the active surveillance group. Further limitations include the variability of Gamma Knife models and radiosurgical techniques utilized and the absence of quality of life and performance status data.

\section{Conclusions}

As compared to active surveillance, SRS confers superior radiological control of asymptomatic, skullbased meningiomas, and it does so without increasing the risk for neurological morbidity. SRS is an alternative to active surveillance as the initial management of patients presenting with an asymptomatic skull base meningioma. If active surveillance is the initial management of choice, SRS should be recommended when radiologic tumor progression is noted and prior to clinical progression. Unfortunately, active surveillance does not precisely define the time of continued tumor growth nor do so necessarily prior to onset of neurological deficits in patients with asymptomatic meningiomas.

\section{Declarations}

Funding: No funding was received for conducting this study

Conflict of interests: L. Dade Lunsford is a shareholder in Elekta $A B$, the manufacturer of some radiosurgical devices. Roman Liscak is a consultant for Elekta AB. All remaining authors certify that they have no affiliations with or involvement in any organization or entity with any financial interest or non-financial interest in the subject matter or materials discussed in this manuscript. 
Ethics approval: The participating centers obtained approval by the local institutional review boards for the study and for sharing de-identified data with the coordinating office

Data availability: The datasets generated during and/or analysed during the current study are available from the corresponding author on reasonable request.

\section{Author contributions}

Conceptualization: Jason Sheehan, Methodology: Jason Sheehan, Formal analysis and investigation: Georgios Mantziaris, Stylianos Pikis, Jason Sheehan, Writing - original draft preparation: Georgios Mantziaris, Writing - review and editing: All authors, Supervision: Jason Sheehan

\section{References}

1. Chamoun R, Krisht KM, Couldwell WT (2011) Incidental meningiomas. Neurosurgical Focus 31:E19. https://doi.org/10.3171/2011.9.FOCUS11220

2. Nakamura M, Roser F, Michel J, et al (2003) The Natural History of Incidental Meningiomas. Neurosurgery 53:62-71. https://doi.org/10.1227/01.NEU.0000068730.76856.58

3. Hashimoto N, Rabo CS, Okita Y, et al (2012) Slower growth of skull base meningiomas compared with non-skull base meningiomas based on volumetric and biological studies: Clinical article. Journal of Neurosurgery 116:574-580. https://doi.org/10.3171/2011.11.JNS11999

4. Pikis S, Bunevicius A, Sheehan J (2021) Outcomes from treatment of asymptomatic skull base meningioma with stereotactic radiosurgery. Acta Neurochir 163:83-88. https://doi.org/10.1007/s00701-020-04648-4

5. Zeng L, Wang L, Ye F, et al (2015) Clinical characteristics of patients with asymptomatic intracranial meningiomas and results of their surgical management. Neurosurg Rev 38:481-488, discussion 488. https://doi.org/10.1007/s10143-015-0619-1

6. Goldbrunner R, Stavrinou P, Jenkinson MD, et al (2021) EANO guideline on the diagnosis and management of meningiomas. Neuro Oncol noab150. https://doi.org/10.1093/neuonc/noab150

7. Sughrue ME, Rutkowski MJ, Aranda D, et al (2010) Treatment decision making based on the published natural history and growth rate of small meningiomas: A review and meta-analysis. Journal of Neurosurgery 113:1036-1042. https://doi.org/10.3171/2010.3.JNS091966

8. Oya S, Kim S-H, Sade B, Lee JH (2011) The natural history of intracranial meningiomas: Clinical article. Journal of Neurosurgery 114:1250-1256. https://doi.org/10.3171/2010.12.JNS101623

9. Sheehan J, Pikis S, Islim A, et al (2021) An International Multicenter Matched Cohort Analysis of Incidental Meningioma Progression During Active Surveillance or After Stereotactic Radiosurgery: The IMPASSE Study. Neuro-Oncology. https://doi.org/10.1093/neuonc/noab132

10. Huang RY, Bi WL, Weller M, et al (2019) Proposed response assessment and endpoints for meningioma clinical trials: report from the Response Assessment in Neuro-Oncology Working Group. Neuro Oncol 21:26-36. https://doi.org/10.1093/neuonc/noy137 
11. Barnett GH, Linskey ME, Adler JR, et al (2007) Stereotactic radiosurgery-an organized neurosurgerysanctioned definition. J Neurosurg 106:1-5. https://doi.org/10.3171/jns.2007.106.1.1

12. R Core Team (2020). R: A language and environment for statistical computing. R Foundation for Statistical Computing, Vienna, Austria. URL https://www.R-project.org/

13. RStudio Team (2020). RStudio: Integrated Development Environment for R. RStudio, PBC, Boston, MA URL http://www.rstudio.com/.

14. Islim Al, Mohan M, Moon RDC, et al (2019) Incidental intracranial meningiomas: a systematic review and meta-analysis of prognostic factors and outcomes. J Neurooncol 142:211-221. https://doi.org/10.1007/s11060-019-03104-3

15. Meling TR, Da Broi M, Scheie D, Helseth E (2019) Meningiomas: skull base versus non-skull base. Neurosurg Rev 42:163-173. https://doi.org/10.1007/s10143-018-0976-7

16. Youden WJ (1950) Index for rating diagnostic tests. Cancer 3:32-35. https://doi.org/10.1002/10970142(1950)3:1<32::AID-CNCR2820030106>3.0.C0,2-3

17. Rubin G, Herscovici Z, Laviv Y, et al (2011) Outcome of untreated meningiomas. Isr Med Assoc J 13:157-160

18. Lee EJ, Kim JH, Park ES, et al (2017) A novel weighted scoring system for estimating the risk of rapid growth in untreated intracranial meningiomas. Journal of Neurosurgery 127:971-980. https://doi.org/10.3171/2016.9.JNS161669

19. Goldbrunner R, Minniti G, Preusser M, et al (2016) EANO guidelines for the diagnosis and treatment of meningiomas. The Lancet Oncology 17:e383-e391. https://doi.org/10.1016/S14702045(16)30321-7

20. Bir SC, Patra DP, Maiti TK, et al (2017) Direct Comparison of Gamma Knife Radiosurgery and Microsurgery for Small Size Meningiomas. World Neurosurg 101:170-179. https://doi.org/10.1016/j.wneu.2017.01.105

21. Gupta A, Xu Z, Cohen-Inbar O, et al (2019) Treatment of Asymptomatic Meningioma With Gamma Knife Radiosurgery: Long-Term Follow-up With Volumetric Assessment and Clinical Outcome. Neurosurgery 85:E889-E899. https://doi.org/10.1093/neuros/nyz126

22. Kim KH, Kang SJ, Choi J-W, et al (2018) Clinical and radiological outcomes of proactive Gamma Knife surgery for asymptomatic meningiomas compared with the natural course without intervention. Journal of Neurosurgery 130:1740-1749. https://doi.org/10.3171/2017.12.JNS171943

23. Islim Al, Mohan M, Moon RDC, et al (2019) Incidental intracranial meningiomas: a systematic review and meta-analysis of prognostic factors and outcomes. J Neurooncol 142:211-221. https://doi.org/10.1007/s11060-019-03104-3

24. Bindal R, Goodman JM, Kawasaki A, et al (2003) The natural history of untreated skull base meningiomas. Surgical Neurology 59:87-92. https://doi.org/10.1016/S0090-3019(02)00995-3

25. Goldbrunner R, Stavrinou P, Jenkinson MD, et al (2021) EANO guideline on the diagnosis and management of meningiomas. Neuro-Oncology. https://doi.org/10.1093/neuonc/noab150 
26. Nakamura M, Struck M, Roser F, et al (2008) OLFACTORY GROOVE MENINGIOMAS: CLINICAL OUTCOME AND RECURRENCE RATES AFTER TUMOR REMOVAL THROUGH THE FRONTOLATERAL AND BIFRONTAL APPROACH. Neurosurgery 62:844-852. https://doi.org/10.1227/01.NEU.0000333788.83349.1E

27. Nakamura M, Roser F, Dormiani M, et al (2005) Facial and cochlear nerve function after surgery of cerebellopontine angle meningiomas. Neurosurgery 57:77-90, discussion 77-90. https://doi.org/10.1227/01.neu.0000154699.29796.34

28. Bambakidis NC, Kakarla UK, Kim LJ, et al (2008) EVOLUTION OF SURGICAL APPROACHES IN THE TREATMENT OF PETROCLIVAL MENINGIOMAS: A RETROSPECTIVE REVIEW. Neurosurgery 62:ONS202-ONS211. https://doi.org/10.1227/01.NEU.0000333784.04435.65

29. Chen C-M, Huang AP-H, Kuo L-T, Tu Y-K (2011) Contemporary surgical outcome for skull base meningiomas. Neurosurg Rev 34:281-296. https://doi.org/10.1007/s10143-011-0321-x

30. Sheehan JP, Lee C-C, Xu Z, et al (2015) Edema following Gamma Knife radiosurgery for parasagittal and parafalcine meningiomas. J Neurosurg 123:1287-1293.

https://doi.org/10.3171/2014.12.JNS142159

31. Daou BJ, Palmateer G, Wilkinson DA, et al (2021) Radiation-Induced Imaging Changes and Cerebral Edema following Stereotactic Radiosurgery for Brain AVMs. AJNR Am J Neuroradiol 42:82-87. https://doi.org/10.3174/ajnr.A6880

32. O'Connor KP, Algan O, Vesely SK, et al (2019) Factors Associated with Treatment Failure and Radiosurgery-Related Edema in WHO Grade 1 and 2 Meningioma Patients Receiving Gamma Knife Radiosurgery. World Neurosurg 130:e558-e565. https://doi.org/10.1016/j.wneu.2019.06.152

33. Ganz JC, Reda WA, Abdelkarim K (2009) Adverse radiation effects after Gamma Knife Surgery in relation to dose and volume. Acta Neurochir (Wien) 151:9-19. https://doi.org/10.1007/s00701-0080174-4

\section{Tables}

Table 1. Patient and tumor baseline data and patient outcomes of matched cohorts 


\begin{tabular}{|c|c|c|c|c|}
\hline & $\begin{array}{l}\text { Total } \\
(n=220)\end{array}$ & $\begin{array}{l}\text { SRS } \\
(n=110)\end{array}$ & $\begin{array}{l}\text { Surveillance } \\
(n=110)\end{array}$ & $\begin{array}{l}\text { Statistical } \\
\text { difference }\end{array}$ \\
\hline Age, mean in years SD) & $63(11.7)$ & $\begin{array}{l}62.9 \\
(12.3)\end{array}$ & $63.23(11.1)$ & 0.82 \\
\hline Male, number (\%) & $\begin{array}{l}57(25.9 \\
\%)\end{array}$ & $\begin{array}{l}28(25.5 \\
\%)\end{array}$ & $29(26.4 \%)$ & 1 \\
\hline Baseline KPS median (IQR) & $100(10)$ & $100(10)$ & $100(10)$ & 0.72 \\
\hline Diameter, mean mm (SD) & $19.1(8.8)$ & $18.8(9.5)$ & $19.4(8.1)$ & 0.62 \\
\hline Volume, mean cm3 (SD) & $3.8(4.1)$ & $3.9(3.2)$ & $3.7(4.8)$ & 0.72 \\
\hline $\begin{array}{l}\text { Imaging follow-up, median in months } \\
\text { (IQR) }\end{array}$ & $42(43.3)$ & $\begin{array}{l}45.5 \\
(43.8)\end{array}$ & $42(42.3)$ & 0.42 \\
\hline $\begin{array}{l}\text { Clinical follow-up, median in months } \\
\text { (IQR) }\end{array}$ & $42(44.3)$ & $47(48.5)$ & $42(42.3)$ & 0.27 \\
\hline $\begin{array}{l}\text { Patients exhibiting neurological } \\
\text { deficits }\end{array}$ & $9(4.1 \%)$ & $3(2.7 \%)$ & $6(5.5 \%)$ & 0.89 \\
\hline Radiologic outcomes & & & & $<0.001$ \\
\hline Tumor progressed & $44(20 \%)$ & $2(1.8 \%)$ & $42(38.2 \%)$ & \\
\hline Tumor stable & $\begin{array}{l}136 \\
(61.9 \%)\end{array}$ & $\begin{array}{l}69(62.7 \\
\%)\end{array}$ & $67(60.9 \%)$ & \\
\hline Tumor regressed & $\begin{array}{l}40(18.2 \\
\%)\end{array}$ & $\begin{array}{l}39(35.5 \\
\%)\end{array}$ & $1(0.9 \%)$ & \\
\hline \multicolumn{5}{|c|}{$\begin{array}{l}\text { SRS = Stereotactic radiosurgery, KPS = Karnofsky performance status, IQR = Interquartile range, } \\
\text { SD = Standard deviation }\end{array}$} \\
\hline
\end{tabular}

Table 2. Radiosurgical treatment parameters of SRS cohorts 


\begin{tabular}{|lll|}
\hline & $\begin{array}{l}\text { Unmatched SRS } \\
\text { Cohort }(\mathrm{n}=307)\end{array}$ & $\begin{array}{l}\text { Matched SRS } \\
\text { Cohort }(\mathrm{n}=110)\end{array}$ \\
\hline Number of fractions & $292(95.1 \%)$ & $106(96.4 \%)$ \\
\hline One & $3(1 \%)$ & 0 \\
\hline Two & $4(1.3 \%)$ & 0 \\
\hline Three & $2(0.7 \%)$ & 0 \\
\hline Four & $6(2 \%)$ & $4(3.6 \%)$ \\
\hline Five & $12.8(2)$ & $13.1(2.3)$ \\
\hline Margin dose, mean Gy (SD) & $25.5(5.2)$ & $25.8(6)$ \\
\hline Maximum dose, mean Gy (SD) & $10(8)$ & $10(10)$ \\
\hline Isocenters, median (IQR) & & \\
\hline SRS = Stereotactic radiosurgery, IQR $=$ Interquartile range, SD $=$ Standard deviation \\
\hline
\end{tabular}

Table 3. Cox regression analysis for risk factors of tumor progression 


\begin{tabular}{|c|c|c|c|c|}
\hline & \multicolumn{2}{|c|}{$\begin{array}{l}\text { Unmatched } \\
\text { Cohorts }(n=417)\end{array}$} & \multicolumn{2}{|c|}{$\begin{array}{l}\text { Matched } \\
\text { Cohorts }(n=220)\end{array}$} \\
\hline & $\underline{\text { Univariate }}$ & $\underline{\text { Multivariate }}$ & $\underline{\text { Univariate }}$ & Multivariate \\
\hline & $\mathrm{p}$-value & $\mathrm{p}$-value & $\mathrm{p}$-value & $\mathrm{p}$-value \\
\hline & $\mathrm{HR}(95 \% \mathrm{Cl})$ & $\mathrm{HR}(95 \% \mathrm{Cl})$ & $\mathrm{HR}(95 \% \mathrm{Cl})$ & $\mathrm{HR}(95 \% \mathrm{Cl})$ \\
\hline \multirow[t]{2}{*}{ Increasing age } & 0.33 & - & 0.03 & 0.39 \\
\hline & & & $1.03(1-1.06)$ & \\
\hline Male gender & 0.44 & 0.11 & 0.29 & 0.12 \\
\hline Increasing baseline KPS & 0.66 & - & 0.47 & - \\
\hline $\begin{array}{l}\text { Increasing tumor } \\
\text { diameter }\end{array}$ & 0.18 & 0.4 & 0.79 & 0.11 \\
\hline $\begin{array}{l}\text { Increasing tumor } \\
\text { volume }\end{array}$ & 0.44 & - & 0.96 & 0.1 \\
\hline $\begin{array}{l}\text { Tumor location } \\
\text { in posterior fossa }\end{array}$ & 0.4 & - & 0.31 & - \\
\hline \multirow[t]{2}{*}{ SRS treatment } & $<0.001$ & $<0.001$ & $<0.001$ & $<0.001$ \\
\hline & $\begin{array}{l}0.01(0.003- \\
0.05)\end{array}$ & $\begin{array}{l}0.01(0.003- \\
0.05)\end{array}$ & $\begin{array}{l}0.02(0.003- \\
0.15)\end{array}$ & $\begin{array}{l}0.01(0.002- \\
0.13)\end{array}$ \\
\hline
\end{tabular}

Table 4. Cox regression analysis for risk factors of neurologic deficit 


\begin{tabular}{|c|c|c|c|c|}
\hline & Unmatched & & Matched & \\
\hline & Cohorts $(n=417)$ & & Cohorts $(n=2$ & \\
\hline & $\underline{\text { Univariate }}$ & $\underline{\text { Multivariate }}$ & $\underline{\text { Univariate }}$ & Multivariate \\
\hline & $p$-value & $p$-value & $p$-value & $\mathrm{p}$-value \\
\hline & $\mathrm{HR}(95 \% \mathrm{Cl})$ & $\mathrm{HR}(95 \% \mathrm{Cl})$ & HR (95\% Cl) & $\mathrm{HR}(95 \% \mathrm{Cl})$ \\
\hline Increasing age & 0.91 & - & 0.52 & - \\
\hline Male gender & 0.9 & - & 0.87 & - \\
\hline Increasing baseline KPS & 0.11 & 0.17 & 0.89 & - \\
\hline Increasing tumor diameter & 0.1 & - & 0.14 & - \\
\hline Increasing tumor volume & 0.001 & $<0.001$ & 0.06 & 0.09 \\
\hline & $1.2(1.1-1.3)$ & $1.16(1.06-1.27)$ & & \\
\hline $\begin{array}{l}\text { Tumor location } \\
\text { in posterior fossa }\end{array}$ & 0.56 & - & 0.1 & 0.1 \\
\hline SRS treatment & 0.02 & 0.02 & 0.22 & 0.21 \\
\hline & $0.21(0.06-0.79)$ & $0.22(0.05-0.78)$ & & \\
\hline
\end{tabular}

Table 5. Cox regression analysis for risk factors for SRS complications (neurologic deficits, asymptomatic AREs) 


\begin{tabular}{|c|c|c|c|c|}
\hline & \multicolumn{2}{|l|}{ AREs } & \multicolumn{2}{|l|}{ Deficits } \\
\hline & $\underline{\text { Univariate }}$ & Multivariate & $\underline{\text { Univariate }}$ & Multivariate \\
\hline & $\mathrm{p}$-value & $\mathrm{p}$-value & $\mathrm{p}$-value & $\mathrm{p}$-value \\
\hline & $\mathrm{HR}(95 \% \mathrm{Cl})$ & $\mathrm{HR}(95 \% \mathrm{Cl})$ & $\mathrm{HR}(95 \% \mathrm{Cl})$ & $\mathrm{HR}(95 \% \mathrm{Cl})$ \\
\hline Increasing age & 0.61 & 0.4 & 0.99 & - \\
\hline Male gender & 0.32 & - & 0.46 & - \\
\hline Increasing baseline KPS & 0.52 & - & 0.12 & 0.29 \\
\hline Tumor volume & 0.003 & 0.02 & 0.15 & 0.69 \\
\hline$>3.5 \mathrm{ml}$ & $4.5(1.7-12)$ & $3.24(1.16-9.03)$ & & \\
\hline $\begin{array}{l}\text { Location } \\
\text { in posterior fossa }\end{array}$ & 0.66 & 0.4 & 0.83 & - \\
\hline Margin dose & 0.02 & 0.04 & 0.58 & \\
\hline$>13.5 \mathrm{~Gy}$ & $2.6(1.2-5.6)$ & $2.36(1.02-5.5)$ & & \\
\hline \multirow[t]{2}{*}{ Isocenters } & 0.002 & 0.09 & $<0.001$ & 0.008 \\
\hline & $1.1(1-1.1)$ & & $1.1(1-1.1)$ & $1.05(1.01-1.09)$ \\
\hline \multirow[t]{2}{*}{ Hypofractionated treatment } & 0.38 & - & 0.02 & 0.09 \\
\hline & & & $6.7(1.3-33)$ & \\
\hline
\end{tabular}

\section{Figures}

A

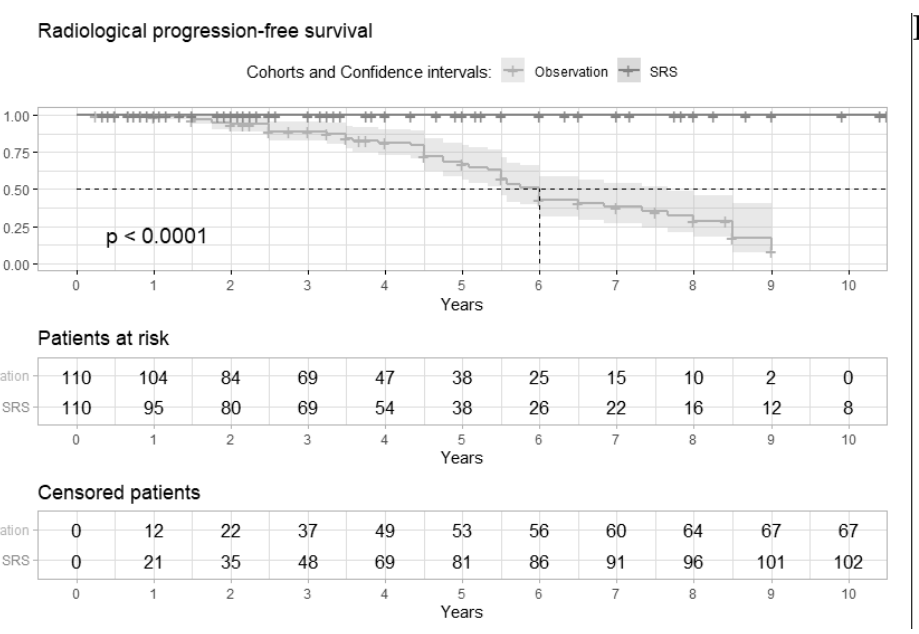

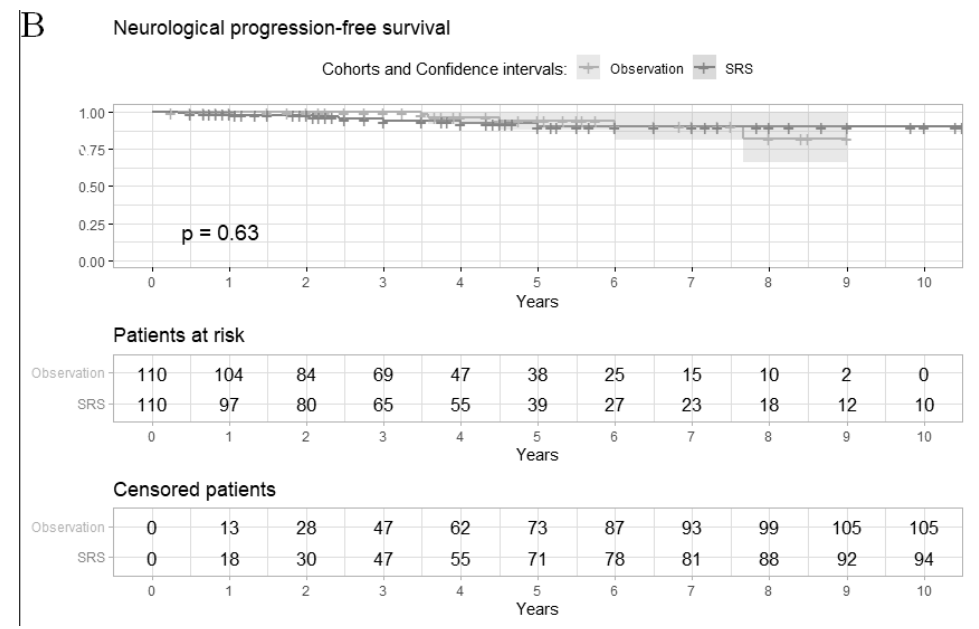

Figure 1 
Kaplan-Meier curves for the matched cohorts, (A) Radiological progression-free survival was in favor of the SRS group $(p<0.0001)$, while (B) neurological progression-free survival was not appreciably different $(p=0.63)$ 